\title{
QUEDA DE PRESSÃO ESTÁTICA POR MEIO DE UMA COLUNA DE NOZ MACADÂMIA
}

\author{
MARCO A. M. BIAGGIONI ${ }^{1}$, PEDRO L. B. TOLEDO PIZA ${ }^{2}$, WIDSNEY A. FERREIRA ${ }^{3}$
}

RESUMO: As unidades de beneficiamento de macadâmia adotam silos secadores distintos, para cada etapa de secagem, a fim de garantir a manutenção da qualidade do produto pela redução da umidade a níveis desejáveis. Diante da necessidade de quantificar a resistência apresentada pelas nozes, submetidas a diferentes fluxos de ar durante a secagem, bem como avaliar a possibilidade de utilização de modelos empíricos, que estimem o gradiente de pressão a partir da vazão de ar, conduziram-se vários testes em laboratório para obtenção de dados experimentais e ajuste de modelos. Frutos de macadâmia ( $M$. integrifolia), com umidade de 0,11 b.s., após limpeza e classificação, foram colocados no interior de um protótipo constituído por uma coluna de chapa galvanizada (com tomadas para medição da pressão estática), plenum e ventilador, sendo submetidos a diferentes fluxos de ar. Os testes consistiram de três medidas por profundidade, para cada um dos três lotes de nozes, perfazendo um total de nove medidas de pressão estática por profundidade na coluna. Os resultados obtidos permitiram concluir que os fluxos de ar testados apresentaram efeito significativo sobre a queda de pressão estática na coluna de macadâmia, a qual aumentou linearmente com a profundidade. Os dados experimentais ajustaram-se muito bem aos modelos de Shedd e Hunter, sugerindo sua boa aplicabilidade para a macadâmia.

PALAVRAS-CHAVE: gradiente de pressão estática, modelos empíricos, macadâmia.

\section{STATIC PRESSURE DROP THROUGH A COLUMN OF MACADAMIA NUT}

\begin{abstract}
The macadamia processing units use different drying silos, for each drying stage, in order to reduce nuts-in-shell moisture content. Due to the need to quantify the resistance presented by the nuts submitted to different drying airflows, as well as, to evaluate the use of empiric models that predicted pressure losses from airflow, it was carried out several tests in laboratory to obtain experimental data and adjustment of models. Macadamia nuts (M. integrifolia) with 0.11 b.s. moisture content after cleaning and classification were placed into an apparatus constituted by a column of galvanized sheet (in different positions for measuring the static pressure), plenum and fan, being submitted to different airflows. The tests consisted of three repetitions (measures), with three lots of nuts, bringing up to nine measures of static pressure for each position in the column. The obtained results allowed to conclude that the tested airflows showed significant effect on the static air pressure in the macadamia column, which increased lineally with the depth. The experimental data adjusted very well to the Shedd and Hunter's models, suggesting their good suitability for macadamia.
\end{abstract}

KEYWORDS: gradient of static pressure, empiric models, macadamia nut.

\footnotetext{
${ }^{1}$ Prof. Dr., Departamento de Engenharia Rural, UNESP - Câmpus de Botucatu - SP, Fone: (0XX14) 3811.7165, biaggioni@ fca.unesp.br

${ }^{2}$ Pós-Graduando em Agronomia/Energia na Agricultura, Departamento de Engenharia Rural, UNESP - Câmpus de Botucatu - SP, Fone: (0XX14) 3811.7165, queennut@ netsite.com.br

${ }^{3}$ Prof. Titular, Departamento de Engenharia Rural, UNESP - Câmpus de Botucatu - SP, Fone: (0XX14) 3811.7165, widsney@fca.unesp.br

Recebido pelo Conselho Editorial em: 12-9-2003

Aprovado pelo Conselho Editorial em: 8-8-2005
} 


\section{INTRODUÇÃO}

Nativa da Austrália, a nogueira macadâmia possui amêndoa que pode ser consumida crua, em doces e pratos finos, ou torrada e salgada na forma de petiscos. Seu óleo, rico em ácido palmitoleico, é disputado pela indústria de cosméticos, na composição de hidratantes, e por laboratórios farmacêuticos, como redutor dos níveis de colesterol (TOLEDO PIZA, 2000).

Para ser consumida, a macadâmia deve ser beneficiada após a colheita. Nesse processo, composto resumidamente pelas operações de recebimento, secagem, quebra da noz, separação amêndoa-casca, classificação, embalagem e expedição, a secagem é considerada, segundo GIULIANI (1982), uma das etapas mais críticas, pois a condução inadequada dessa fase acarreta graves danos ao produto.

As unidades de beneficiamento de macadâmia mais modernas, inclusive no Brasil, adotam silos secadores distintos, com ar natural ou aquecido, para cada etapa de secagem, permitindo estabelecer fluxo contínuo de matéria-prima para o processamento. Estudos de secagem da macadâmia vêm sendo amplamente desenvolvidos na Austrália, empregando silos de seção quadrada e fundo inclinado. No Brasil, poucos trabalhos de pesquisa têm sido realizados sobre secagem de macadâmia, em escala real de operação, utilizando apenas um silo para todas as etapas de secagem ou um silo para cada etapa (XAVIER et al., 1998).

É fundamental que a umidade da noz em casca, recém-colhida, seja reduzida de 0,20 a 0,25 b.s. (base seca) para 0,035 b.s., prevenindo a rápida deterioração e facilitando a extração da amêndoa. Na indústria, a secagem é atualmente realizada com ar aquecido circulando continuamente por meio da massa de nozes armazenada. O'HARE \& VOCK (1990) sugeriram que o fruto fresco da macadâmia deve ser seco na fazenda, em silos aerados, imediatamente após o descarpelamento, tendo sua umidade em casca reduzida de 0,20 para 0,10 b.s. Nozes com essa umidade podem ser armazenadas em silos aerados por até quatro semanas; para longas estocagens, recomenda-se umidade de 0,015 b.s.

MASON (1999) enfatizou que os produtores não devem secar a macadâmia até 0,035 b.s. porque as amêndoas serão danificadas no transporte. Por outro lado, o transporte de nozes com alta umidade ( $>0,10$ b.s.) pode produzir manchas marrons nas amêndoas. A recomendação final é que as nozes devem ser secas até 0,075 b.s., na fazenda, e transportadas para a fábrica, quando terão a umidade reduzida para 0,035 b.s.

HOBSON (1991) recomendou o início do processo de secagem imediatamente após o descarpelamento, devendo-se insuflar ar à temperatura ambiente à velocidade de $0,25 \mathrm{a} 0,27 \mathrm{~m} \mathrm{~s}^{-1}$ na massa. Segundo ainda o autor, o aumento dessa velocidade pode causar trincas e quebra nas nozes sem, contudo, acelerar o processo de secagem.

Estudando a secagem e o escoamento de noz macadâmia em silo secador de fundo cônico, TOLEDO PIZA (2000) trabalhou com vazão de ar de $64,68 \mathrm{~m}^{3} \mathrm{~min}^{-1}$ e velocidade frontal de $0,086 \mathrm{~ms}^{-1}$. Segundo o autor, esses valores ficaram aquém daqueles recomendados pela literatura, comprometendo o desempenho do sistema de secagem. $\mathrm{O}$ uso de equipamentos subdimensionados tornou o processo de secagem mais lento e, operacionalmente, mais difícil.

As relações entre o volume de ar que atravessa a massa do produto, a resistência oferecida à passagem do ar e a altura da camada do produto, acima do sistema de distribuição, são importantes no projeto, seleção e operação de equipamentos de movimentação de ar. Como os custos de instalação e operação de tais dispositivos estão se tornado, dia a dia, mais importantes, faz-se necessário que o projetista de sistemas de processamento de produtos agrícolas esteja apto a selecionar e aplicar o melhor equipamento de distribuição de ar, levando em consideração os fatores técnicos e econômicos envolvidos no projeto. 
A queda de pressão estática de uma camada de grãos ou sementes, quando atravessada por um fluxo de ar, é comumente estimada por meio de curvas empíricas, relacionando fluxo de ar e pressão estática. A literatura reporta o desenvolvimento de diversos modelos para simular a variação da pressão numa massa armazenada. SHEDD (1953) apresentou um gráfico em escala logarítmica contendo curvas conhecidas como "Curvas de Shedd", relacionando a densidade do fluxo de ar e a queda de pressão para 22 tipos de grãos. Devido à convexidade das curvas, SHEDD (1953) recomendou o uso do seguinte modelo para pequenas faixas de fluxos de ar:

$$
\mathrm{V}=\mathrm{a} \Delta \mathrm{P}^{\mathrm{b}}
$$

em que,

$\mathrm{V}$ - densidade do fluxo de ar, $\mathrm{m}^{3} \mathrm{~s}^{-1} \mathrm{~m}^{-2}$

$\Delta \mathrm{P}$ - queda de pressão, $\mathrm{Pa} \mathrm{m}^{-1}$, e

$\mathrm{a}, \mathrm{b}$ - constantes obtidas no ajuste dos dados experimentais.

HUNTER (1983) desenvolveu estudo sobre a diferença de pressão por meio de massa de grãos. Em seu trabalho, representou o modelo de ERGUN (1952) pela seguinte fórmula simplificada:

$$
\Delta \mathrm{P}=\mathrm{MV}+\mathrm{NV}^{2}
$$

Os coeficientes $\mathrm{M}$ e $\mathrm{N}$ englobam os parâmetros do fluido e da massa granular, requeridos pela formulação de Ergun. Esses coeficientes resultam, portanto, do ajuste dos dados experimentais ao modelo. Essa abordagem leva em conta que, para baixas taxas de escoamento, a queda de pressão é proporcional à densidade do fluxo de ar, enquanto, para altas vazões, a proporcionalidade varia com o quadrado do fluxo (ERGUN,1952).

Segundo AFONSO (1994), a principal razão para a utilização da eq.(2) é a simplicidade, quando aplicada ao estudo de distribuição não-uniforme do fluxo de ar em silos.

Considerando a existência de poucas informações abordando a resistência que a noz macadâmia oferece à passagem de ar, o presente trabalho tem por objetivos obter dados experimentais da distribuição da pressão estática em uma camada vertical de noz macadâmia, para diferentes fluxos de ar, e avaliar a possibilidade de utilização de modelos empíricos, que estimem o gradiente de pressão estática a partir da vazão de ar, a fim de fornecer subsídios na seleção de equipamentos de ventilação.

\section{MATERIAL E MÉTODOS}

O trabalho foi desenvolvido na Faculdade de Ciências Agronômicas, da UNESP - Câmpus de Botucatu, junto ao Laboratório de Processamento de Produtos Agrícolas, pertencente ao Departamento de Engenharia Rural.

Frutos de macadâmia em casca $\left(M\right.$. integrifolia), com umidade de 0,11 b.s. (estufa a $105^{\circ} \mathrm{C}$ $\pm 3{ }^{\circ} \mathrm{C}$ durante 24 horas), após limpeza e classificação, foram colocados no interior do protótipo, esquematizado na Figura 1, constituído por: (1) coluna de chapa galvanizada, medindo 1,20 m de altura, com seção circular de $0,50 \mathrm{~m}$ de diâmetro; (2) tomadas para medição da pressão estática, representadas por cinco tubos de cobre ( $5 \mathrm{~mm}$ de diâmetro) distanciados em 0,20 m, verticalmente, em torno da coluna; (3) piso perfurado, em chapa com furos circulares; (4) câmara plenum, em madeira, de seção quadrada $(0,55 \times 0,55 \mathrm{~m})$, com $0,33 \mathrm{~m}$ de altura; (5) tubo de chapa galvanizada, medindo $1,20 \mathrm{~m}$ de comprimento por $0,12 \mathrm{~m}$ de diâmetro, responsável pela condução do ar insuflado pelo ventilador até o plenum; (6) homogeneizador para uniformização do fluxo de ar; (7) ventilador centrífugo de pás retas, marca Blasi, modelo VC 30, acionado por motor elétrico com potência de $1 / 3$ cv; (8) diafragma fixo à entrada de ar, permitindo a variação da vazão; (9) cone redutor; (10) tomada para velocidade. 
Os testes de queda de pressão foram realizados com três lotes diferentes de macadâmia. Em cada lote, realizaram-se três medidas em cada uma das cinco tomadas de pressão estática, perfazendo um total de nove medidas de pressão estática por profundidade na coluna.

$\mathrm{O}$ ar insuflado no sistema atingiu velocidades médias de 12,0;8,5;5,0 e 2,7 $\mathrm{m} \mathrm{s}^{-1}$, medidas com anemômetro de hélice (OTA KEIKI, 0-100.000 m; 1,0 m). Pela equação da continuidade, chegou-se aos fluxos médios de 7,80;14,38;24,55 e 34,57 $\mathrm{m}^{3} \mathrm{~min}^{-1} \mathrm{~m}^{-2}$, respectivamente. Para a leitura da diferença de pressão estática, utilizou-se manômetro diferencial de tubo inclinado $\left(18^{\circ}\right)$, marca Dwyer, precisão de $0,5 \mathrm{~mm}$ de coluna d'água. $\mathrm{O}$ enchimento da coluna foi feito com o produto em queda livre, acerca de um metro do piso perfurado.

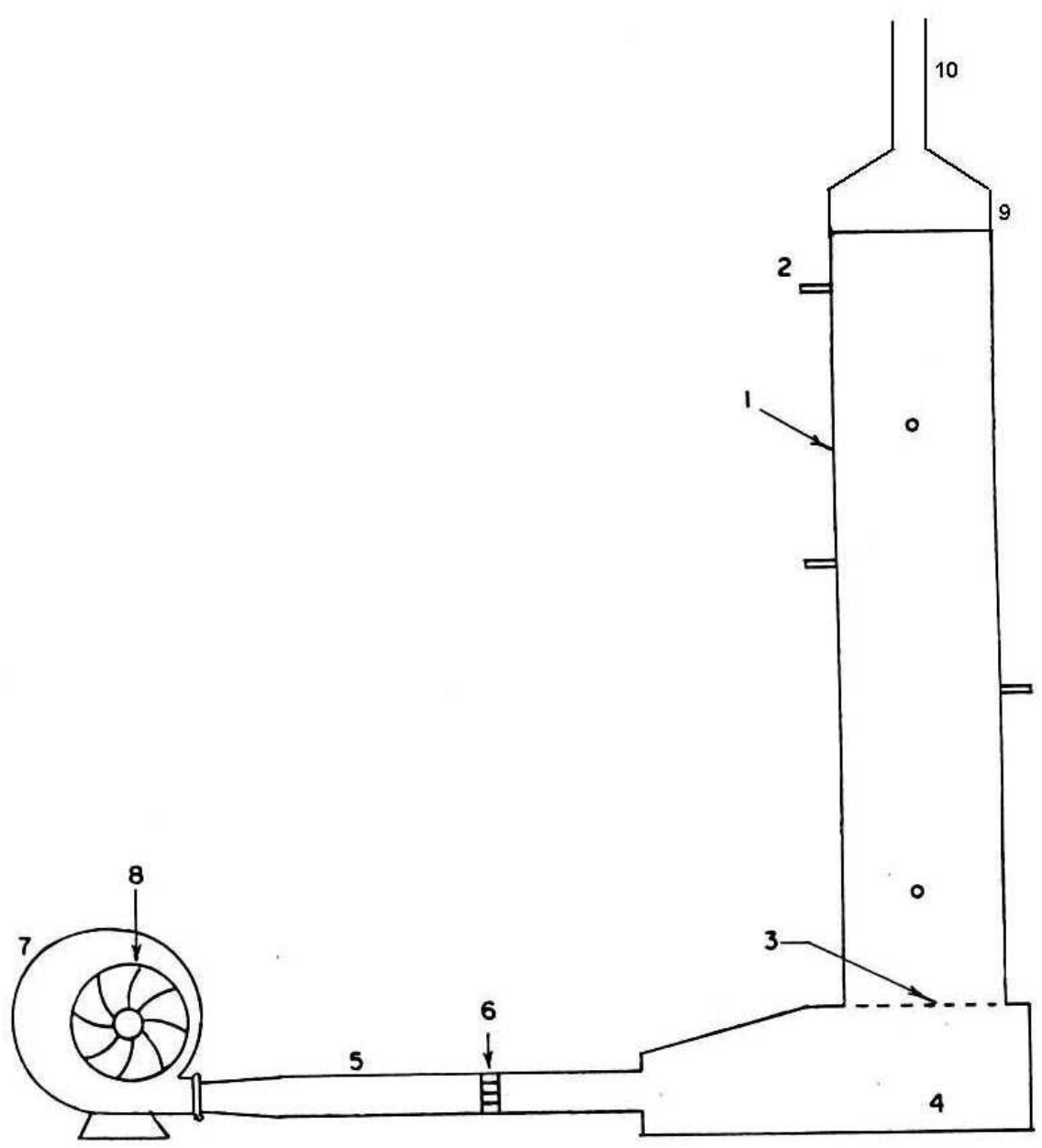

FIGURA 1. Esquema do protótipo utilizado na determinação do gradiente de pressão estática.

Para a caracterização física da macadâmia, cinco amostras por lote, pesando cerca de $5 \mathrm{~kg}$ cada, foram retiradas após cada teste. Além da determinação da umidade, as amostras foram submetidas a análises de massa específica aparente (massa de nozes num volume de $1.000 \mathrm{~mL}$ ), massa específica real (deslocamento de óleo), diâmetro (paquímetro digital), massa (balança analítica) das nozes e porosidade, conforme eq.(3):

$$
\mathrm{S}=\left(1-\frac{\rho_{\mathrm{ap}}}{\rho_{\mathrm{r}}}\right) 100
$$


em que,

$\mathrm{S}$ - porosidade, $\%$

$\rho_{\text {ap }}$ - massa específica aparente, $\mathrm{kg} \mathrm{m}^{-3}$, e

$\rho_{\mathrm{r}}$ - massa específica real, $\mathrm{kg} \mathrm{m}^{-3}$.

O monitoramento do ar ambiente do laboratório onde se desenvolveram os testes, próximo ao diafragma do ventilador, foi realizado por meio de termoigrômetro digital, da marca TESTO, modelo $171-3$, faixa de medição -10 a $+50{ }^{\circ} \mathrm{C}\left( \pm 0,6{ }^{\circ} \mathrm{C}\right)$ e 0 a $100 \%( \pm 3 \%)$.

Para avaliar o efeito das diferentes densidades de ar testadas, sobre a queda de pressão estática, foi adotado um delineamento experimental inteiramente casualizado, com nove repetições e quatro níveis de fluxo de ar, adotando-se o teste de Tukey, a 1\% de probabilidade, para a comparação das médias dos tratamentos.

Os modelos empíricos testados neste trabalho foram os propostos por SHEDD (1953) e HUNTER (1983). Assim, os dados de gradiente de pressão e densidade de fluxo de ar, obtidos experimentalmente, foram utilizados para ajustar, por meio de análises de regressão simples, aos modelos, determinando-se os parâmetros a e b da eq.(1) e $\mathrm{M}$ e $\mathrm{N}$ da eq.(2). Os critérios para a determinação do melhor ajuste foram o coeficiente de determinação $\left(\mathrm{R}^{2}\right)$ e o desvio percentual médio $(\mathrm{P})$ :

$$
\mathrm{P}=\frac{100}{\mathrm{n}} \sum_{\mathrm{i}=1}^{\mathrm{n}} \frac{\left|\Delta \mathrm{P}_{\text {exp }}-\Delta \mathrm{P}_{\text {calc }}\right|}{\Delta \mathrm{P}_{\exp }}
$$

em que,

$\mathrm{P}$ - desvio percentual médio, \%;

$\mathrm{n}$ - quantidade de dados experimentais;

$\Delta \mathrm{P}_{\exp }$ - valores de gradiente de pressão obtidos experimentalmente, $\mathrm{Pa} \mathrm{m}^{-1}$, e

$\Delta \mathrm{P}_{\text {calc }}$ - valores de gradiente de pressão preditos pelo modelo, $\mathrm{Pa} \mathrm{m}^{-1}$.

\section{RESULTADOS E DISCUSSÃO}

Os valores médios de massa específica aparente, massa específica real, porosidade, diâmetro médio e massa das nozes, obtidos após a realização de cada teste, em cinco repetições, são apresentados na Tabela 1. A temperatura e a umidade relativa médias do ar, durante os testes, variaram de 25 a $26^{\circ} \mathrm{C}$ e 68 a $77 \%$, respectivamente. Como, para todos os testes, as variações de temperatura e umidade relativa foram inferiores a $1,5^{\circ} \mathrm{C}$ e $10 \%$, respectivamente, não houve necessidade de correções nos valores do volume específico do ar para o cálculo da densidade do fluxo de ar.

TABELA 1. Médias e desvio-padrão obtidos com os dados de massa específica aparente, massa específica real, porosidade, diâmetro e massa da noz de macadâmia utilizada nos testes.

\begin{tabular}{lrrrrrr}
\hline & \multicolumn{2}{c}{ Lote 1 } & \multicolumn{2}{c}{ Lote 2 } & \multicolumn{2}{c}{ Lote 3 } \\
\cline { 2 - 6 } & Média & Desvio & Média & Desvio & Média & Desvio \\
\hline Massa Específica Aparente $\left(\mathrm{kg} \mathrm{m}^{-3}\right)$ & 535,53 & 6,97 & 527,59 & 9,82 & 526,88 & 8,68 \\
Massa específica real $\left(\mathrm{kg} \mathrm{m}^{-3}\right)$ & $1.005,13$ & 13,05 & 961,87 & 18,04 & 985,77 & 20,28 \\
Porosidade (\%) & 46,72 & 1,08 & 45,15 & 1,78 & 46,55 & 0,93 \\
Diâmetro médio (mm) & 25,14 & 1,18 & 25,20 & 0,83 & 25,21 & 1,11 \\
Massa (g) & 8,16 & 0,50 & 7,45 & 1,11 & 8,82 & 1,20 \\
\hline
\end{tabular}

A variação da pressão estática na coluna de macadâmia, medida em cinco profundidades e quatro densidades de fluxo de ar, é apresentada na Figura 2. Verifica-se, em todos os testes realizados, 
o comportamento praticamente linear da curva de pressão estática em relação à profundidade da camada de macadâmia. Observa-se, ainda, inclinação crescente das curvas obtidas com os maiores fluxos de ar, corroborando o comportamento apresentado por outros produtos como canola (SANTOS et al., 1999), café em coco (AFONSO, 1994) e grãos de cereais (ASAE, 1995).

Na Figura 3 e Tabela 2, são apresentados os valores de gradiente de pressão obtidos nos testes. Verifica-se que, nos três lotes utilizados, as curvas obtidas praticamente coincidiram, principalmente nos fluxos mais altos, denotando a boa uniformidade do produto (Figura 3). Para a faixa de fluxo de ar utilizada ( 8 a $35 \mathrm{~m}^{3} \mathrm{~min}^{-1} \mathrm{~m}^{-2}$ ), a queda de pressão estática, por metro de coluna de macadâmia, variou de 13 a $210 \mathrm{~Pa}$, aproximadamente. A comparação entre médias (Tabela 2) mostra diferença significativa para todas as densidades de fluxo de ar testadas, sugerindo a sensível influência dessa variável na resistência ao fluxo de ar.

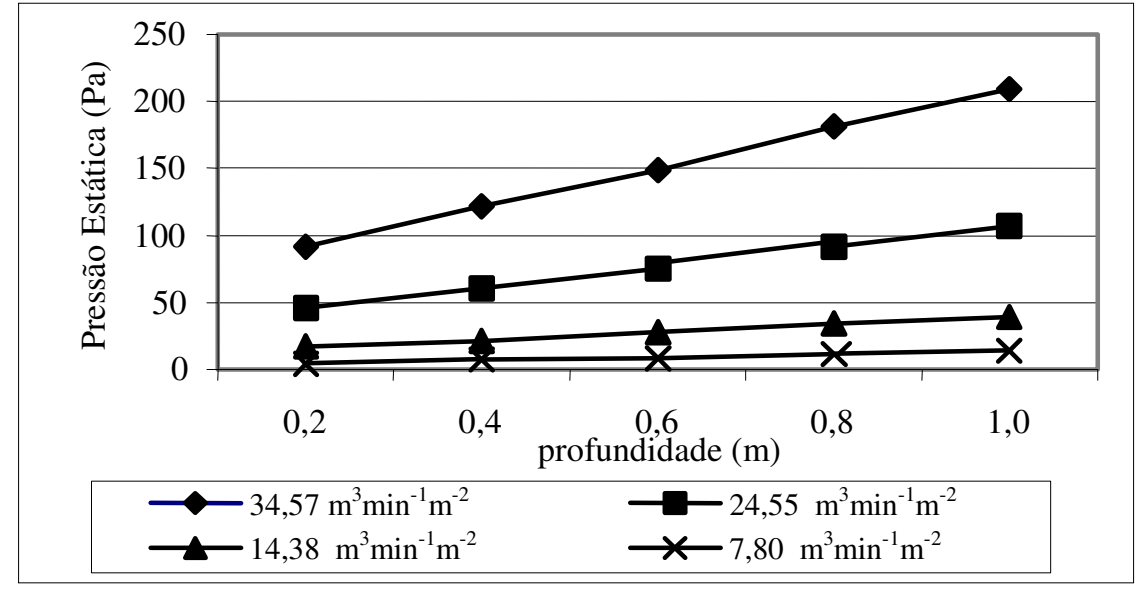

FIGURA 2. Efeitos da profundidade da camada e da densidade do fluxo de ar sobre a variação da pressão estática numa coluna de macadâmia.

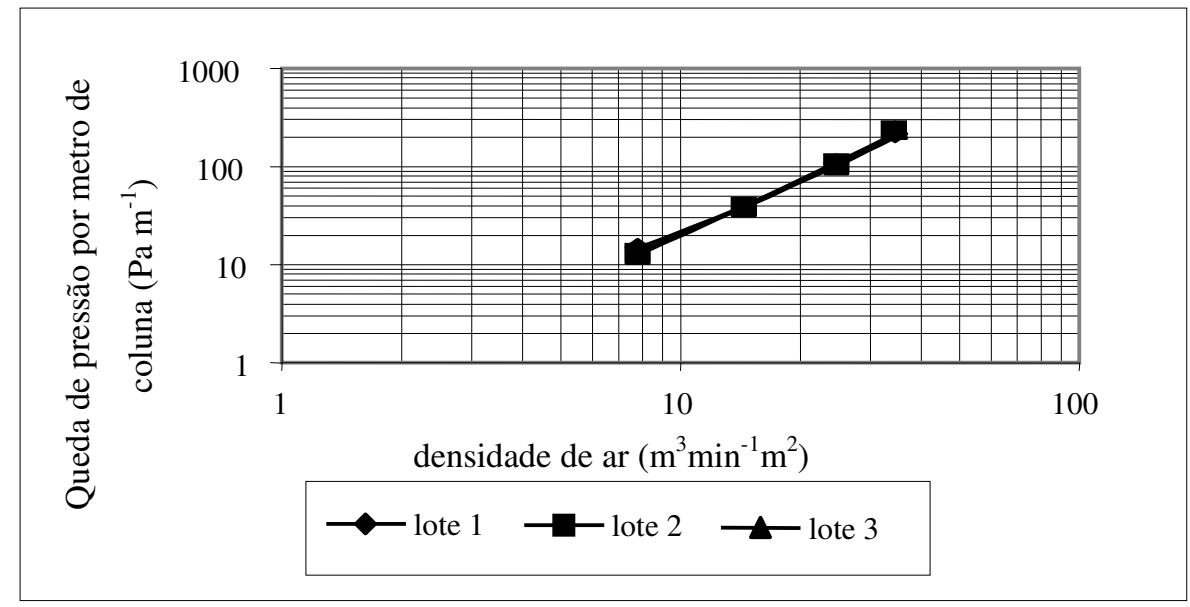

FIGURA 3. Curvas de queda de pressão estática, por metro de coluna, em macadâmia em casca, obtidas em três lotes testados.

Na Figura 4, a variação do gradiente de pressão estática da macadâmia, em função das diferentes densidades de fluxo de ar investigadas neste trabalho, pode ser comparada com a da soja, do milho e do trigo, estimadas pelo modelo proposto por HUKILL \& IVES (ASAE, 1995). Verifica-se que, dependendo da densidade do fluxo de ar, o gradiente de pressão estática da macadâmia é de 7 a 12 vezes menor que o da soja, 11 a 16 vezes menor que o do milho e 24 a 44 vezes menor que o do trigo. 
TABELA 2. Comparação das médias de gradiente de pressão estática, em função da densidade do fluxo de ar, pelo teste de Tukey ${ }^{1}$.

\begin{tabular}{ccc}
\hline $\begin{array}{c}\text { Densidade do Fluxo de } \mathrm{Ar} \\
\left(\mathrm{m}^{3} \min ^{-1} \mathrm{~m}^{-2}\right)\end{array}$ & \multicolumn{2}{c}{ Gradiente de Pressão Estática $\left(\mathrm{Pa} \mathrm{m}^{-1}\right)$} \\
\cline { 2 - 3 } 34,57 & $209,37 \mathrm{~A}$ & Desvios \\
24,55 & $107,03 \mathrm{~B}$ & 7,72 \\
14,38 & $39,28 \mathrm{C}$ & 3,94 \\
7,80 & $13,56 \mathrm{D}$ & 1,10 \\
\hline
\end{tabular}

${ }^{1}$ Médias seguidas da mesma letra não diferem significativamente entre si, pelo Teste de Tukey, a $1 \%$ de probabilidade.

Coeficiente de variação (C.V.): 4,78\%

Desvio mínimo significativo (dms): 7,02 $\mathrm{Pa} \mathrm{m}^{-1}$

Embora a porosidade do produto permita ao ar atravessá-lo, o tamanho e a forma dos vários tipos de grãos também governam sua resistência à passagem do ar, que se intensifica quanto menor o grão e maiores a densidade do ar, a profundidade do leito e o teor de impurezas. Assim, no caso do trigo, apesar de apresentar maior porosidade $(41 \%)$ em relação à soja $(35 \%)$ e ao milho $(40 \%)$, a resistência oferecida é maior devido, basicamente, à pequena dimensão e forma irregular. A esfericidade desse produto, ou seja, o grau de aproximação da forma do trigo com a esfera atinge apenas 0,54. A menor resistência oferecida pela soja, mesmo apresentando menor porosidade, pode ser creditada a sua forma mais regular (0,85 de esfericidade), aproximando-se mais da forma esférica $(1,00)$.

Essas observações mostram que sistemas de ventilação destinados à macadâmia, se projetados com dados de gradiente de pressão de outros produtos agrícolas, estarão superdimensionados, gerando maior consumo de energia.

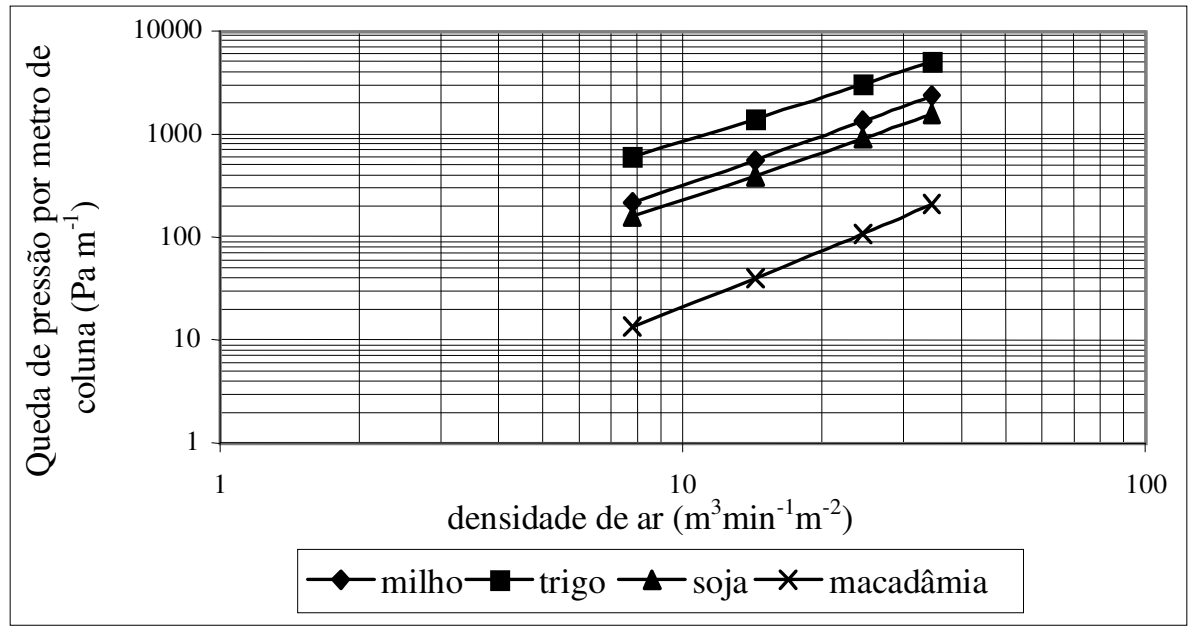

FIGURA 4. Comparação entre as curvas de queda de pressão da macadâmia em casca, por metro de coluna, obtida experimentalmente, e a de alguns cereais estimadas pelo modelo proposto por Hukill \& Ives (ASAE, 1995).

Os coeficientes a e b, do modelo de Shedd, e M e N, do modelo de Hunter, são apresentados na Tabela 3, juntamente com os respectivos coeficientes de determinação $\left(R^{2}\right)$ e desvios percentuais médios $(\mathrm{P})$. Os valores dos coeficientes de determinação, muito próximos de 1, indicam o bom ajuste dos dois modelos testados, sugerindo a boa aplicabilidade dos mesmos também para a macadâmia em casca. No caso do modelo de Hunter, entretanto, sugere-se a inclusão da constante K na equação, já que não foi possível obter bom ajuste na sua forma original:

$$
\Delta \mathrm{P}=\mathrm{K}+\mathrm{MV}+\mathrm{NV}^{2}
$$

em que K é uma constante. 
Analisando-se pelos erros percentuais médios $(\mathrm{P})$, todos abaixo de $3 \%$, também se verifica o bom ajuste, ficando, inclusive, bem abaixo do limite considerado por GOMES et al. (2003) para bom ajuste dos dados experimentais ao modelo, que é um valor inferior a 5\%. Por esse último critério, o modelo de Hunter apresenta o melhor ajuste, com erro médio de, apenas, 0,5\%.

TABELA 3. Desvio percentual médio (P) e coeficientes de determinação $\left(\mathrm{R}^{2}\right)$ e dos modelos de Shedd e Hunter, obtidos por meio de regressão, para a noz macadâmia.

\begin{tabular}{cl}
\hline Shedd & Hunter \\
\hline $\mathrm{P}=2,7 \%$ & $\mathrm{P}=0,5 \%$ \\
$\mathrm{R}^{2}=0,9957$ & $\mathrm{R}^{2}=0,9964$ \\
$\mathrm{a}=1,9338$ & $\mathrm{M}=0,0518$ \\
$\mathrm{~b}=0,5418$ & $\mathrm{~N}=0,1712$ \\
- & $\mathrm{K}=2,8650$ \\
\hline
\end{tabular}

Nas Figura 5 e 6, a variação do gradiente de pressão estática da macadâmia, em função das diferentes densidades de fluxo de ar investigadas neste trabalho, pode ser comparada com as curvas fornecidas pelos modelos empíricos de Shedd e Hunter, respectivamente. Verifica-se que os dois modelos praticamente coincidem, na faixa de densidade de fluxo de ar testada, com os dados experimentais, apresentando pequeno afastamento para fluxos maiores que deve ser investigado em trabalhos futuros.

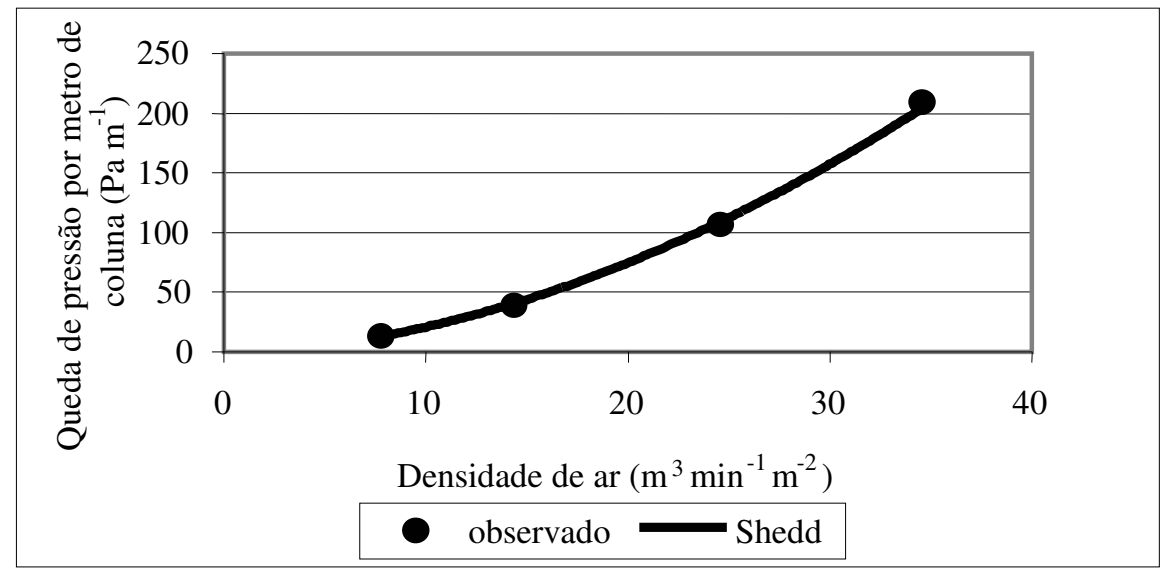

FIGURA 5. Comparação entre as curvas de queda de pressão estática para macadâmia em casca, obtidas experimentalmente e pelo modelo de Shedd.

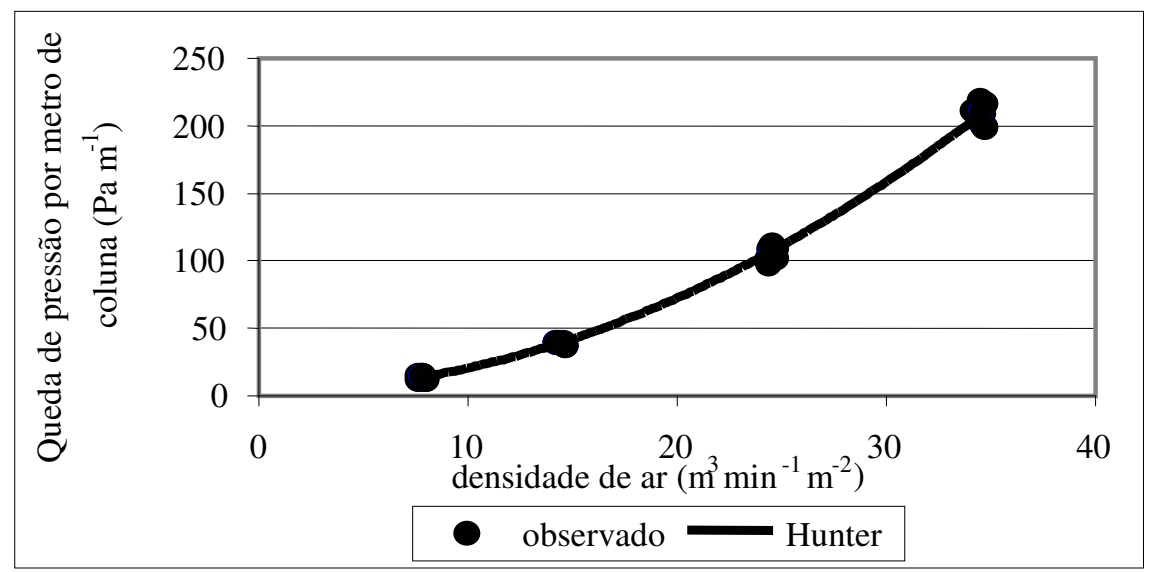

FIGURA 6. Comparação entre as curvas de queda de pressão estática para macadâmia em casca, obtidas experimentalmente e pelo modelo de Hunter. 


\section{CONCLUSÕES}

A pressão estática aumentou linearmente com a profundidade da coluna vertical de macadâmia em casca, para cada densidade de fluxo de ar.

Todas as vazões de ar testadas apresentaram efeito significativo na variação da queda de pressão estática, ocorrendo as maiores perdas de pressão com as maiores vazões.

Os valores de queda de pressão estática oferecidos pela macadâmia são baixos em relação aos principais grãos de cereais, evidenciando a importância da porosidade do leito no escoamento do ar.

Os modelos de Shedd e Hunter, para predizer os gradientes de pressão estática em macadâmia em casca, ajustaram-se bem aos dados experimentais na faixa de fluxo de ar investigada.

\section{REFERÊNCIAS}

AFONSO, A.D.L. Gradiente de pressão estática em camadas de frutos de café (Coffea arabica $L$.) com diferentes teores de umidade. 1994. 68 f. Dissertação (Mestrado em Armazenamento) Universidade Federal de Viçosa, Viçosa - MG, 1994.

AMERICAN SOCIETY OF AGRICULTURAL ENGINEERS. ASAE standards 1995: Standards Engineering Pratices Data. $42^{\text {th }}$ ed. St. Joseph: ASAE, 1995. 463 p.

ERGUN, S. Fluid flow through packed columns. Chemical Engineering Progress, New York, v.48, n.2, p.89-94, 1952.

GIULIANI, F. La macadamia. Rivista di Agricoltura Subtropicale e Tropicale, São Jose, Costa Rica, v.76, n.1/2, p.103-61, 1982.

GOMES, P.M.A.; FIGUEIREDO, R.M.F.; QUEIROZ, A.J.M. Avaliação de modelos matemáticos de isotermas de sorção de umidade em acerola em pó. In: CONGRESSO BRASILEIRO DE ENGENHARIA AGRÍCOLA, 32., 2003, Goiânia. Anais... Jaboticabal: Sociedade Brasileira de Engenharia Agrícola, 2003. 1 CD-ROM.

HOBSON, L. Macadamia harvesting and handling. In: MACADAMIA MINI SYMPOSIUM, 1991, Tzaneen, África do Sul. Proceedings... Tzaneen, África do Sul: SAMAC, 1991. p.30-4.

HUNTER, A.J. Pressure difference across an aerated seed bulk for some common duct and store crosssections. Journal of Agricutural Engineering Research, London, v.28, n.5, p.437-50, 1983.

MASON, R.L. The processing challenge: macadamia nut quality research, past, present and future. In: INTERNACIONAL MACADMIA SYMPOSIUM IN AFRICA, 1., 1999, Nelspruit, South Africa.

Proceedings... Tzaneen, South Africa: The Southern African Macadamia Grower's Association, 1999. p.171-81.

O'HARE, P.; VOCK, N. Growing macadamias in Queensland. Nambour: Queensland Department of Primary Industries, 1990. 36 p. (RQN90007)

SANTOS, V.P.; DAMASCENO, G.S.; CORRÊA, P.C.; SINICIO, R. Estudo da resistência ao fluxo de ar em uma camada de canola iciola-41 (Brassica napus L. var. oleifera). Engenharia Agrícola, Jaboticabal, v.18, n.3, p.101-10, 1999.

SHEDD, C.K. Resistance of grains and seeds to air flow. Agricutural Engineering, St. Joseph, v.34, n.9, p.616-9, 1953.

TOLEDO PIZA, P.L.B. Secagem e escoamento da noz macadâmia (M. integrifolia) em silo secador de fundo cônico. 2000. 102 f. Dissertação (Mestrado em Energia na Agricultura) - Faculdade de Ciências Agronômicas, Universidade Estadual Paulista, Botucatu, 2000.

XAVIER, J.A.; TOLEDO PIZA, J.A.N.; TOLEDO PIZA, P.L.B.; XAVIER, A.P. Estudo da distribuição de temperatura em silo secador para noz macadâmia. In: CONGRESSO BRASILEIRO DE ENGENHARIA AGRÍCOLA, 27., 1998, Poços de Caldas. Anais...Lavras: Sociedade Brasileira de Engenharia Agrícola, 1998. v.4, p.112-4. 